\section{US synchrotron radiation}

\section{Cautious start on new sources}

Washington

THE US Congress has finally given the Department of Energy (DoE) the goahead to start pre-construction research and development for the next two major synchrotron light sources. The fiscal year 1986 appropriation for DoE, now awaiting President Reagan's signature, includes $\$ 5$ million for the design of both a $6 \mathrm{GeV}$ machine providing hard $X$ rays and a 2 $\mathrm{GeV}$ high brilliance machine optimized for the vacuum ultraviolet and soft X-ray regions. (The energies are those of the circulating electrons stored in the rings.)

The case for the new machines has been emphasized in several recent studies. Decisions have been spurred by the perception that Europe may be stealing a march on the United States with the possibility that a European 5-6 GeV synchrotron may be built at Grenoble (see Nature 315, $362 ; 1985$ ). But Congress, having recently suffered several painful experiences with major physics facilities, has said that support for pre-construction research does not imply a commitment to go ahead with construction. The $2 \mathrm{GeV}$ machine is expected to cost between $\$ 75$ and $\$ 100$ million and the $6 \mathrm{GeV}$ machine about twice as much. Construction would probably be financed through DoE, with the National Science Foundation (NSF) helping with planning and design.

Both machines will make maximum use of insertion devices, the value of which in increasing flux densities has been fully realized only in the past few years. Much of the initial research will concentrate on designs with several parallel insertion devices and on optics capable of handling radiation 1,000 times brighter than what is now the brightest US source of $\mathrm{X}$ rays and ultraviolet radiation, at the National Synchrotron Light Source at Brookhaven National Laboratory. Other existing US synchrotron light sources are at Stanford Linear Accelerator Center, Cornell University, the National Bureau of Standards in Maryland and the University of Wisconsin.

While formal decisions on construction still lie ahead, the competition to play host to one or other of the new sources has inevitably begun. Argonne National Laboratory in Illinois is making a strong pitch for the $6 \mathrm{GeV}$ hard X-ray source, while Lawrence Berkeley Laboratory in California is pushing for the smaller machine. Several workshops have been held to look at design possibilities.

The most recent recommendations on synchrotron priorities were given at a briefing last month by IBM's Dean Eastman to NSF and DoE officials. Eastman confirmed the findings of his previous report on the subject a year before, conducted for the National Research Council, which gave the $6 \mathrm{GeV}$ machine top prior- ity. But Eastman was faced with the delicate question of whether the problems experienced by the $800 \mathrm{MeV}$ Aladdin machine at the University of Wisconsin and the recent progress towards solving them - should lead to a reassessment of priorities.

Design faults in Aladdin created serious problems with beam stability, so that early this year, after 4 years of adjustments, the maximum beam current was still a paltry $2.5 \mathrm{~mA}$. More recently, the incorporation of ion-clearing magnets has increased beam currents to $40 \mathrm{~mA}$, and further increases are expected, but it is clear Aladdin will never approach its design current of $1 \mathrm{amp}$. Eastman was not persuaded that a major upgrade for Aladdin could substitute for the planned new $2 \mathrm{GeV}$ machine.

Indeed, NSF cut off funds for Aladdin on 30 September, but David Huber, director of the Wisconsin Synchrotron Radiation Center, has nevertheless defiantly transferred beam lines from the adjacent $240 \mathrm{MeV}$ Tantalus ring to Aladdin and is hoping to persuade NSF to renew its support on the grounds that even $40 \mathrm{~mA}$ will be useful to materials science researchers. He says that Aladdin (which, as a mark of shame, had had its name taken away by NSF) is now producing more intense light over its entire spectrum than could Tantalus. But Huber will have to persuade NSF to provide another $\$ 2$ million a year to operate Aladdin instead of Tantalus, which may not be easy, given that NSF has already once decided to wash its hands of the project.

According to Louis Ianniello, director of materials science at DoE, the experi-
Anticipating that its income will increase

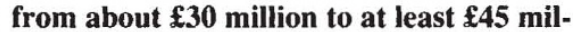
lion next year, the Wellcome Trust hopes to spend up to $£ 10$ million annually on permanent research groups within UK universities, instead of supporting medical research only with short-term grants as it does now.

The extra income will come from the trust's sale, early next year, of one-fifth of the shares in the Wellcome Foundation, the pharmaceutical company that has been wholly owned by the trust since both were set up under the will of Sir Henry Dale. This year, the trust expects to receive about $£ 30$ million out of the profits of the foundation. Next year, it hopes earn £1520 million in interest by investing the proceeds of the share flotation on the stock market. The problem for Dr Peter Williams, the trust's director, is how to attract sufficiently good proposals on which to spend the extra income.

It is likely, he says, that most of the

ence with Aladdin "hasn't changed anything" that would affect planning for future machines. And Lewis Nosanow, his opposite number at NSF, says the design problems of synchrotrons are now largely understood - Nosanow believes that to build neither of the two proposed machines would be "a disaster". and is adamant that both are needed. Congress might decide otherwise.

Tim Beardsley

- The European Synchrotron Radiation Facility (ESRF), now firmly planned for Grenoble by a Franco-German bilateral decision, is still looking for cash. So far, France has offered to pay 39 per cent of the construction costs, West Germany 29 per cent and Italy 15 per cent. This leaves 17 per cent to find.

There have been hopes in France and Britain that a deal could be struck in which France would invest in a portion of the UK Science and Engineering Research Council's Spallation Neutron Source (SNS), which is still short of operating funds, in return for an equal investment by Britain in ESRF. But this is opposed by some leading scientists in France, who have to find users for the many neutron sources already available there. "The last thing we need is more neutrons", they say.

The ministry of research in Paris, however, is still trying to strike a deal, emphasizing that there are many experiments to be done on the pulsed SNS that could not be done anywhere else. So the saga of ESRF, first proposed by the European Science Foundation in 1973 as a facility that would give Europe a lead over the United States, continues. The news from the United States indicating that Europe could yet be overtaken will add bitterness and urgency to the story.

Robert Walgate

\title{
Wellcome aid for research
}

money will be spent on basic biomedical sciences, and three new advisory panels have just been set up to identify promising areas of research. But Williams is concerned that morale is so low in UK universities as to inhibit applications, and he is considering the need to attract British scientists back from the United States.

Williams is also concerned lest the increase in the Wellcome Trust's investments in UK university medical research is used as an excuse by the government to cut back on its own support. This is provided through the Medical Research Council, whose spending in universities will be matched by the trust next year.

No further sales of shares are at present planned by the trust but it may eventually sell up to 49 per cent of them. To exceed that would entail a loss of the trust's controlling interest, which would be even more contrary to the stipulation's of Sir Henry Dale's will than the present sale.

Peter Newmark 